\title{
GOBERNANZA Y NUEVA ORGANIZACIÓN ADMINISTRATIVA EN LA RECIENTE LEGISLACIÓN ESPAÑOLA Y DE LA UNIÓN EUROPEA SOBRE CONTRATACIÓN PÚBLICA
}

\author{
JOSÉ ANTONIO MORENO MOLINA ${ }^{\top}$ \\ Universidad de Castilla-La Mancha \\ joseantonio.moreno@uclm.es
}

Cómo citar/Citation

Moreno Molina, J. A. (2017).

Gobernanza y nueva organización administrativa en la reciente legislación española y de la Unión Europea sobre contratación pública. Revista de Administración Pública, 204, 343-373. doi: https://doi.org/10.18042/cepc/rap.204.12

\section{Resumen}

El trabajo analiza las disposiciones sobre gobernanza que introduce como novedad frente a la regulación anterior la Directiva 2014/24/UE sobre contratación pública y su incorporación en la nueva ley española de contratos del sector público, que de forma destacable crea la Oficina de Supervisión de la Contratación, con plena independencia orgánica y funcional. Este nuevo organismo coordinará la supervisión en materia de contratación pública de los poderes adjudicadores del conjunto del sector público con la finalidad de velar por la correcta aplicación de la legislación en esta materia. También se estudian en el artículo las medidas sobre supervisión y control

1 Catedrático de Derecho Administrativo. El presente trabajo se ha realizado en el marco del proyecto de investigación concedido por el Ministerio de Economía y Competitividad del Gobierno de España «La nueva regulación de la contratación pública: hacia un nuevo sistema de gobernanza pública y de actuación de los poderes públicos» (DER2015-67102-C2-1-P). 
de la contratación, el diseño de políticas estratégicas, la nueva organización para establecer una «ventanilla única» nacional respecto a la Unión Europea, y la cooperación interadministrativa.

\section{Palabras clave}

Contratos públicos; gobernanza; principios generales; profesionalización; organización administrativa.

\section{Abstract}

The paper analyzes the provisions on governance that introduces as a novelty in front of the previous regulation the Directive 2014/24/EU on public procurement and its incorporation into the new Spanish law on public sector contracts, which notably creates the Office of Supervision of the Contracting, with full independence, organic and functional independence. This new organization will coordinate public procurement supervision of contracting authorities in the public sector as a whole, in order to ensure the correct application of legislation in this area. Also discussed in the article are the measures on supervision and control of recruitment, the design of strategic policies, the new organization to establish a national "single window" with respect to the European Union and inter-administrative cooperation.

\section{Keywords}

Public procurement; governance; general principles; professionalization; administrative organization. 


\section{SUMARIO}

I. INTRODUCCIÓN. GOBERNANZA Y CONTRATACIÓN PÚBLICA. II. HACIA UNA NUEVA REGULACIÓN QUE IMPULSE EL RESPETO DE LOS PRINCIPIOS GENERALES Y LA PROFESIONALIZACIÓN EN LA GESTIÓN DE LOS CONTRATOS PÚBLICOS. III. LAS DISPOSICIONES SOBRE GOBERNANZA QUE RECOGE LA DIRECTIVA 2014/24/UE Y SU PLASMACIÓN EN ESPAÑA EN LA NUEVA LEY DE CONTRATOS DEL SECTOR PÚBLICO: 1. Supervisión de la contratación, informes y control de la aplicación de la normativa: 1.1. Obligaciones de los Estados miembros. 1.2. Deberes de los poderes adjudicadores. 1.3. La lamentable carencia de estadísticas sobre contratación pública en la Unión Europea y en España. 2. Diseño de políticas estratégicas. 3. Punto de contacto único de España: la Junta Consultiva de Contratación Pública del Estado. 4. El Comité de Cooperación en materia de contratación pública y su competencia para la elaboración de la propuesta de Estrategia Nacional de Contratación Pública. 5. La Oficina Independiente de Regulación y Supervisión de la Contratación como pilar del nuevo sistema de gobernanza en el ordenamiento jurídico español. 6. La cooperación entre los Estados miembros: las funciones del Sistema de Información del Mercado Interior en la Unión Europea.

\section{INTRODUCCIÓN. GOBERNANZA Y CONTRATACIÓN PÚBLICA}

El título IV de la Directiva 2014/24/UE del Parlamento Europeo y del Consejo, de 26 de febrero de 2014, sobre contratación pública, recoge unas normas sobre "Gobernanza»" que no tenían antecedente en la regulación anterior, salvo las disposiciones sobre elaboración de informes estadísticos incluidas en el título V («Obligaciones estadísticas, competencias de ejecución y disposiciones finales») de la Directiva 2004/18/CE, sobre coordinación de los procedimientos de adjudicación de los contratos públicos de obras, de suministro y de servicios.

2 J. M. Gimeno Feliú (2014), El nuevo paquete legislativo comunitario sobre contratación pública: de la burocracia a la estrategia (el contrato público como herramienta del liderazgo institucional de los poderes públicos), Cizur Menor: Aranzadi, págs. 39 y ss. 
Ahora bien, lo ambicioso de la denominación del título IV de la nueva Directiva no nos debe llevar a falsas expectativas, porque son pocas las previsiones que contiene y limitado su alcance.

Dentro de las diferentes connotaciones y significados del concepto de gobernanza, se puede partir de la definición de Cerrillo de que la gobernanza está constituida por las normas y reglas que pautan la interacción en el marco de redes de actores públicos, privados y sociales, interdependientes en la definición del interés general en entornos complejos y dinámicos, asociándose sobre todo la idea de gobernanza a una mayor implicación de actores no gubernamentales en el diseño e implementación de las políticas públicas ${ }^{3}$.

También el Libro Blanco sobre la gobernanza de la Unión Europea ${ }^{4}$ plantea la necesidad de impulsar una mayor participación de todos los actores sociales y fija entre los principios de una buena gobernanza los de apertura, participación, responsabilidad, eficacia y coherencia.

Pero las normas y obligaciones que recoge la Directiva 2014/24 se dirigen de forma principal a la Comisión, los Estados miembros y los poderes adjudicadores, y se refieren sobre todo a la supervisión de la aplicación de las normas sobre contratación pública, a la información y estadísticas sobre los contratos, y a la cooperación administrativa.

Del conjunto de la nueva regulación europea, así como de la importante jurisprudencia del Tribunal de Justicia de la Unión Europea (TJUE) ${ }^{5}$, sí se desprende en cambio la necesidad de un nuevo paradigma en la contratación pública que garantice el derecho a una buena administración ${ }^{6} \mathrm{y}$ los principios

3 A. Cerrillo i Martínez (2005), "Prólogo», La gobernanza hoy: 10 textos de referencia, Madrid: Instituto Nacional de Administración Pública, pág. 10.

4 Comunicación de la Comisión, de 25 de julio de 2001, «La gobernanza europea. Un Libro Blanco» (COM (2001) 428 final - Diario Oficial C 287 de 12.10.2001).

5 Véase J. M. Gimeno Feliú (2015), «El valor interpretativo de las directivas comunitarias sobre contratación pública y del derecho pretoriano. Las opciones de transposición en España en la propuesta de reforma», Observatorio de Contratos Públicos 2014, Cizur Menor: Aranzadi, págs. 23 y ss.

6 El derecho fundamental a la buena administración se consagró en la Carta de los Derechos Fundamentales de la Unión Europea, que los presidentes del Parlamento Europeo, del Consejo y de la Comisión firmaron y proclamaron el 7 de diciembre de 2000 con ocasión del Consejo Europeo de Niza, y que tiene desde la entrada en vigor del Tratado de Lisboa, el 1 de diciembre de 2009, «el mismo valor jurídico que los Tratados» (art. 6 del Tratado de la Unión Europea (TUE), apdo. 1, párr. primero). Acerca del principio de buena administración aplicado a los contratos públicos puede verse la sentencia del Tribunal General de la UE (Sala Cuarta) de 27 de abril de 2016, asunto T-556/11, Evropaïki Dynamiki, ECLI:EU:T:2016:248. J. Ponce Solé (2016), 
de eficacia, eficiencia, transparencia e integridad ${ }^{7}$. Como destaca con acierto el profesor Gimeno Feliú, nos encontramos ante una nueva realidad jurídicoeconómica de la contratación pública, que exige una visión estratégica en un contexto económico globalizado ${ }^{8}$.

El Tribunal de Cuentas Europeo ha resaltado recientemente que la política de contratación pública es, en nuestros días, un instrumento fundamental para el desarrollo del mercado único, el logro de un crecimiento inteligente, sostenible e integrador, y el uso eficiente y eficaz de los fondos públicos?

\section{HACIA UNA NUEVA REGULACIÓN QUE IMPULSE EL RESPETO DE LOS PRINCIPIOS GENERALES Y LA PROFESIONALIZACIÓN EN LA GESTIÓN DE LOS CONTRATOS PÚBLICOS}

El proceso de trasposición en España de las Directivas 2014/23, 24 y 25 , con la tramitación del proyecto de nueva Ley de Contratos del Sector Público $^{10}$, constituía una excelente oportunidad para plantear una nueva regulación que, en verdad, simplifique e impulse la transparencia, la igualdad, la concurrencia y la uniformidad jurídica en toda la contratación del sector público español ${ }^{11}$.

"La discrecionalidad no puede ser arbitrariedad y debe ser buena administración», en Revista Española de Derecho Administrativo, 175, págs. 57-84; Rastrollo Suárez y García Jiménez (2015), «Buena administración aplicada a los contratos públicos: directiva de recursos, instrumentos de publicidad activa y participación ciudadana», en Las nuevas directivas de contratación pública, Cizur Menor: Aranzadi, págs. 367 y ss. y J. Rodríguez Arana (2012), «El derecho a la buena administración en las relaciones entre ciudadanos y Administración Pública», Anuario da Facultade de Dereito da Universidade da Coruña, 16, págs. 247-274.

7 M. Oller Rubert (2015), «Notas sobre la gobernanza en la contratación pública: el perfil del contratante como instrumento de transparencia», en Contratación administrativa práctica, 135, número especial dedicado a "Transparencia vs. Corrupción», págs. 46-54.

8 Véase J. M. Gimeno Feliú (2015), «El valor interpretativo...», op. cit., pág. 19.

9 Informe especial del Tribunal de Cuentas Europeo 17/2016, «Las instituciones de la UE pueden hacer más para facilitar el acceso a su contratación pública», Luxemburgo, pág. 10.

10 Publicado en el $B O C G \mathrm{n}^{\circ} \mathrm{A}-2-1$, de 2 de diciembre de 2016, pág. 1.

11 J. M. Gimeno Feliú, «El valor interpretativo...», op. cit., págs. 23 y ss. y M. M. Razquin Lizárraga (2015), «Las nuevas directivas sobre contratación pública de 2014: aspectos clave y propuestas para su transformación en España», en RAP, 196, págs. 97 y ss. 
Los objetivos de las nuevas directivas - y los principios que las inspiran- deben servir, para Gimeno Feliú, de modelo general para toda la contratación pública y deben permitir implantar una nueva gobernanza pública que incorpore como paradigmas de la gestión la eficacia, la eficiencia y la integridad que permitan impulsar un modelo armonizado y transparente de gestión de los fondos públicos, que ayuden a consolidar las específicas políticas públicas inherentes a nuestro modelo social y económico, y que impulsen la reactivación económica y empresarial ${ }^{12}$.

El Informe España 2017 de la Comisión Europea ${ }^{13}$ advierte que nuestro país carece de una política de contratación pública a nivel nacional que garantice la competencia y la transparencia. El documento critica que no haya un organismo a nivel nacional que se encargue de asegurar la eficiencia y el cumplimiento de la legalidad vigente de una manera uniforme, lo que puede corregirse con la creación de la nueva Oficina Independiente de Regulación y Supervisión de la Contratación.

Es momento también para actualizar los conceptos y pilares sobre los que se diseñó el modelo institucional del contrato administrativo en Espańa, donde la idea basilar de las "prerrogativas administrativas" cede a favor de un modelo de igualdad de trato, eficiencia e integridad en la gestión de los fondos públicos. La profesora Gallego Córcoles subraya que debe hacerse un esfuerzo por incorporar las nuevas categorías y conceptos ${ }^{14}$.

En este sentido, los principios generales de la contratación pública deben jugar un papel clave. El primer considerando de la Directiva 2014/24 resalta la necesidad de respetar los principios generales en la adjudicación de contratos públicos por las autoridades de los Estados miembros. Se identifican estos principios con los reconocidos por «el Tratado sobre el funcionamiento de la

12 «La reforma comunitaria en materia de contratos públicos y su incidencia en la legislación española. Una visión desde la perspectiva de la integridad», en J. M. Gimeno Feliú, I. Gallego Córcoles, F. Hernández González y J. A. Moreno Molina (2015), Las nuevas directivas de contratación pública (dir. Gimeno Feliú), Cizur Menor: Aranzadi, págs. 36 y ss.

13 Documento de trabajo de los servicios de la Comisión, «Informe del país España 2017» (SWD 2017, 74 final, de 22 de febrero de 2017) y Comunicación de la Comisión al Parlamento Europeo, al Consejo, al Banco Central Europeo y al Eurogrupo «Semestre Europeo 2017: Evaluación de los avances en materia de reformas estructurales, corrección de los desequilibrios macroeconómicos y resultados de las revisiones de acuerdo con el Reglamento (UE) no 1176/2011 01»(COM 2017, 90 final y SWD 2017, 67 final).

14 I. Gallego Córcoles (2015), «La modificación de los contratos en la cuarta generación de directivas sobre contratación pública», en J. M. Gimeno Feliú, I. Gallego Córcoles, F. Hernández González y J. A. Moreno Molina, Las nuevas directivas..., op. cit., págs. 107 y ss. 
Unión Europea y, en particular, la libre circulación de mercancías, la libertad de establecimiento y la libre prestación de servicios, y de los principios derivados de la misma, tales como el de la igualdad de trato, la no discriminación, el reconocimiento mutuo, la proporcionalidad y la transparencia", y se hace alusión reiterada a los mismos a lo largo de toda la exposición de motivos de la Directiva 2014/24/UE (en especial en los considerandos 31, 37, 40, 45, 68, 90, 110, 112 y 114$)$.

En una consolidada doctrina ${ }^{15}$, el TJUE ha reiterado que la obligación de respeto de los principios de objetividad, imparcialidad y no discriminación en la adjudicación de los contratos públicos, que son la esencia de la regulación normativa de estos, se extiende no solo a los limitados contratos que caen dentro del ámbito de aplicación de las directivas comunitarias sobre contratación pública ${ }^{16}$ —en base al cual se fundamenta la cuestionable categoría acuñada por la LCSP 2007 de contratos sujetos a regulación armonizada (arts. 13 y ss. TRLCSP) ${ }^{17}$, mantenida ahora por la LCSP 2017 (arts. 19 y ss.)—, sino también a todos los contratos que celebren los órganos de contratación sometidos a las directivas, ya que así lo exigen distintos preceptos de los tratados de derecho originario, tal y como han sido interpretados por el propio Tribunal.

La nueva norma europea recoge, por tanto, esta jurisprudencia en el frontispicio de la misma y advierte que se aplica para los contratos públicos que se sitúen tanto por debajo como por encima de los umbrales, sin perjuicio

15 Véanse, por todas, las SSTJUE de 29 de abril de 2004, asunto C-496/99, CAS Succhi di Frutta, ECLI: EU: C: 2004: 236; de 13 de octubre de 2005, asunto C-458/03, Parking Brixen GMBH, EU: C: 2005: 605; y de 19 de junio de 2008, asunto C 454/06, Pressetext Nachrichtenagentur, EU: C: 2008: 351.

16 El art. 4 de la Directiva 2014/24/UE, que fue modificado por el Reglamento Delegado (UE) 2015/2170 de la Comisión, de 24 de noviembre de 2015, fija el ámbito de aplicación de la misma estableciendo unos umbrales económicos. La directiva se aplicará a las contrataciones cuyo valor estimado, sin incluir el impuesto sobre el valor añadido (IVA), sea igual o superior a los umbrales siguientes:

(a) 5225000 euros, en los contratos públicos de obras;

(b) 135000 o 209000 euros, en los contratos públicos de suministro y de servicios adjudicados por autoridades gubernamentales centrales o por poderes adjudicadores subcentrales;

(d) 750000 euros, en los contratos públicos de servicios sociales y otros servicios específicos enumerados en el anexo XIV, por el Reglamento Delegado (UE) 2015/2170 de la Comisión, de 24 de noviembre de 2015.

17 J. A. Moreno Molina (2009), «Un mundo para Sara. Una nueva categoría en el Derecho español de la contratación pública: los contratos sujetos a regulación armonizada», Revista de Administración Pública, 178, págs. 175-213. 
de que para estos últimos la propia legislación coordine los procedimientos de adquisición nacionales con el fin de que esos principios se lleve a la práctica.

En esta misma línea, debe recordarse la Comunicación interpretativa de la Comisión Europea, de 23 de junio de 2006, sobre el derecho comunitario aplicable en la adjudicación de contratos no cubiertos o solo parcialmente cubiertos por las directivas sobre contratación pública ${ }^{18}$, cuya legalidad y conformidad con el derecho europeo fue confirmada por la STJUE de 20 de mayo de 2010, en el asunto T-258/06 ${ }^{19}$.

Y el Tribunal Constitucional español, en su Sentencia 84/2015, de 30 de abril de 2015, ha declarado que:

[...] aun cuando el contrato de gestión de servicios públicos no es un contrato armonizado [...], esto es, no está sujeto... a la Directiva 2014/24/UE..., la encomienda por una autoridad pública a un tercero de la prestación de actividades de servicios, debe respetar el principio de igualdad de trato y sus expresiones específicas, que son la prohibición de discriminar en razón de la nacionalidad, y los arts. 43 y 49 del Tratado CE, sobre la libertad de establecimiento y la libre prestación de servicios, respectivamente (FJ 6).

Otro elemento clave de la nueva gobernanza debe ser la profesionalización de los gestores de la contratación ${ }^{20}$. La buena gobernanza en relación con la contratación demanda que los empleados encargados de la contratación pública se conviertan en verdaderos profesionales, que no solo cumplan las normas, sino que además sean directores de la contratación ${ }^{21}$.

Hay que tener en cuenta que, en concordancia con la Estrategia Europa 2020 para un crecimiento inteligente, sostenible e integrador ${ }^{22}$, las directivas sobre contratos públicos de 2014 impulsan un uso estratégico de la contratación

18 Diario Oficial C 179 de 01/08/2006.

19 ECLI: EU: T: 2010: 214.

20 J. M. Gimeno Feliú (2014), «Decálogo de Reglas para prevenir la corrupción en los Contratos Públicos», OBCP (http://www.obcp.es/index.php/mod.opiniones/mem. detalle/id.180/relcategoria.201/relmenu.3/chk.7e86b5e21ba5b19849b3088aecee 5e60, consultado el 28 de noviembre de 2016), que destaca la profesionalización como uno de los factores esenciales para promover la integridad. Véase también E. Malaret (2016), «El nuevo reto de la contratación pública para afianzar la integridad y el control: reforzar el profesionalismo y la transparencia», en Revista Digital de Derecho Administrativo, 15, págs. 21-60.

21 M. A. Sanmartín Mora (2012), «La profesionalización de la contratación pública», en AA. VV., Observatorio de Contratos Públicos 2011 (dirección Gimeno Feliú), Madrid: Civitas, págs. 318 y ss.

22 Documento de la Comisión COM 2010, 2020. 
pública y proponen que los compradores utilicen mejor la contratación pública, elemento clave de las economías nacionales de la $\mathrm{UE}^{23}$, en apoyo de objetivos sociales comunes como la protección del medio ambiente, una mayor eficiencia energética y, en el uso de los recursos, la lucha contra el cambio climático, la promoción de la innovación ${ }^{24}$, el empleo y la integración social, y la prestación de servicios sociales de alta calidad en las mejores condiciones posibles ${ }^{25}$.

También exige una profesionalización de la contratación pública la obligatoriedad para los poderes adjudicadores de utilización de medios electrónicos en todas las comunicaciones y los intercambios de información en los procedimientos de contratación que impone la Directiva 2014/24/UE ${ }^{26}$.

Además de lo anterior, esta profesionalización resulta decisiva para promover la integridad y luchar contra una de las grandes preocupaciones actuales del derecho de la Unión Europea y español en materia de contratación pública, como es la lucha contra la corrupción ${ }^{27}$, que genera pérdidas en la

23 Las autoridades públicas gastan cada año aproximadamente una quinta parte del PIB de la UE en la adquisición de obras, suministros y servicios, como recuerda el Informe especial del Tribunal de Cuentas Europeo 17/2016, cit.

24 P. Valcárcel Fernández (2016), «Impulso de la compra pública para la innovación (CPI) a través de las distintas modalidades de contratación conjunta: análisis de casos», Compra conjunta y demanda agregada en la contratación del sector público: un análisis jurídico y económico, Cizur Menor: Aranzadi, págs. 349 y ss., y (2011) «Impulso decisivo en la consolidación de una contratación pública responsable. Contratos verdes: de la posibilidad a la obligación», en Actualidad Jurídica Ambiental, 1, págs. 16-24.

25 Véase C. Alonso García (2015), «La consideración de la variable ambiental en la contratación por el Reglamento Delegado (UE) 2015/2170 de la Comisión, de 24 de noviembre de 2015, pública en la nueva Directiva europea 2014/24/UE», en La Ley Unión Europea, 26, págs. 5 y ss., y J. Pernás García (2012), «El uso estratégico de la contratación pública como apoyo a las políticas ambientales», en Observatorio de politicas ambientales 2012, Cizur Menor: Civitas, págs. 299-323.

26 R. Martínez Gutiérrez (2015), La Contratación Pública Electrónica: análisis y propuesta de transposición de las directivas comunitarias de 2014, Valencia: Tirant lo Blanch. Acerca de las exigencias y decisivos cambios en la tramitación de los procedimientos de contratación que supone la plena utilización de medios electrónicos, puede verse el Libro Verde de la Comisión sobre la generalización del recurso a la contratación pública electrónica en la Unión Europea (SEC 2010, 1214), y la Comunicación de la Comisión al Parlamento Europeo, al Consejo, al Comité Económico y Social Europeo y al Comité de las Regiones, «Estrategia en pos de la contratación pública electrónica» (COM 2012179 final).

27 Véase J. M. Gimeno Feliú (2016), «La corrupción en la contratación pública. Propuestas para rearmar un modelo desde la perspectiva de la integridad», en J. M. Gimeno Feliú, M. Villoria Mendieta y J. Tejedor Bielsa (dirs.), La corrupción en España: 
economía de la UE por valor de unos 120000 millones de euros al año — 1\% del PIB europeo-, como destacan la Comunicación de la Comisión «Lucha contra la corrupción en la UE» ${ }^{28}$ y el Informe sobre la corrupción en la Unión Europea de $2014^{29}$.

\section{LAS DISPOSICIONES SOBRE GOBERNANZA QUE RECOGE LA DIRECTIVA 2014/24/UE Y SU PLASMACIÓN EN ESPAÑA EN LA NUEVA LEY DE CONTRATOS DEL SECTOR PÚBLICO}

\section{SUPERVISIÓN DE LA CONTRATACIÓN, INFORMES Y CONTROL DE LA APLICACIÓN DE LA NORMATIVA}

\subsection{Obligaciones de los Estados miembros}

El art. 83.2 de la Directiva 2014/24 obliga a los Estados miembros a velar por que «la aplicación de las normas de contratación pública sea supervisada».

De esta forma, cuando las autoridades o estructuras de supervisión detecten incumplimientos específicos o problemas sistémicos, por sus propios medios o por haber recibido información al respecto, estarán facultadas para señalar estos problemas a las autoridades de auditoría, órganos jurisdiccionales u otras autoridades, organismos o estructuras nacionales adecuadas, como el Defensor del Pueblo, los Parlamentos nacionales o las comisiones parlamentarias.

Hay que recordar que las conocidas como directivas de recursos, la 89/665/CEE y la 92/13/CEE, que han sido modificadas por la Directiva $2014 / 23^{30}$, prevén que los procedimientos de recurso en materia de contratos públicos deben ser accesibles, como mínimo, a cualquier persona que tenga o haya tenido interés en obtener un determinado contrato y que se haya visto o pueda verse perjudicada por una presunta infracción del derecho de la

ámbitos, causas y remedios jurídicos, Barcelona: Atelier, págs. 247 y ss.; A. García Jiménez (2015), «Gestión profesional de las licitaciones públicas: propuestas para la nueva ley de contratos del sector público», en Revista Aranzadi Doctrinal, 10, pág. 1, y A. Cerrillo i Martínez (2014), El principio de integridad en la contratación pública, Cizur Menor: Aranzadi.

28 Documento COM (2011) 308 final, de 6 de junio, pág. 3.

29 El texto completo del informe puede encontrarse en la dirección http://ec.europa.eu/ dgs/home-affairs/what-we-do/policies/organized-crime-and-human-trafficking/corruption/anti-corruption-report/index_en.htm (consultado el 10 de marzo de 2017).

30 El art. 46 de la Directiva 2014/23 modifica la Directiva 89/665, mientras que el art. 47 modifica la Directiva 92/13. 
Unión en el ámbito de la contratación pública o de las normas nacionales de aplicación de dicho derecho ${ }^{31}$.

No obstante, la Directiva 2014/24 advierte que los ciudadanos, las partes interesadas, organizadas o no, y otras personas y organismos que no tienen acceso a los procedimientos de recurso con arreglo a las directivas de recursos, sí tienen un interés legítimo, en tanto que contribuyentes, en procedimientos adecuados de contratación. Por ello, quiere ofrecerles la posibilidad, de un modo distinto al del sistema de recurso contemplado en la Directiva 89/665/CEE, y sin que ello implique necesariamente que se les conceda legitimación ante los órganos jurisdiccionales, de señalar posibles infracciones de la normativa sobre contratación pública a la autoridad o la estructura competente.

En este sentido, y para no duplicar las autoridades existentes, la Directiva 2014/24 prevé que los Estados miembros contemplen el recurso a las autoridades o estructuras de supervisión general, a los organismos de supervisión sectorial, a las autoridades municipales de supervisión y a las autoridades nacionales en materia de competencia o de auditoría.

El apdo. 3 del art. 83 de la Directiva 2014/24 señala que los resultados de estas actividades de supervisión se pondrán a disposición del público por los medios de información adecuados. Estos resultados se comunicarán también a la Comisión.

A más tardar el 18 de abril de 2017, y posteriormente cada tres años, los Estados miembros presentarán a la Comisión un informe de supervisión que comprenda, si procede, información sobre las fuentes más frecuentes de aplicación incorrecta o de inseguridad jurídica, por ejemplo, los posibles problemas estructurales o recurrentes en la aplicación de las normas, sobre el nivel de participación de las pymes en la contratación pública ${ }^{32}$ y sobre la prevención, detección y notificación adecuada de los casos de fraude, corrupción, conflicto de intereses y otras irregularidades graves en la contratación.

Cada país también está obligado a asegurar que se pueda acceder gratuitamente a información y orientaciones sobre la interpretación y aplicación de

31 P. Valcárcel Fernández (2016), «El recurso especial en materia de contratos públicos: en la senda del derecho a una buena administración», en F. López Ramón (coord.), Las vias administrativas de recurso a debate: Actas del XI Congreso de la Asociación Española de Profesores de Derecho Administrativo, Madrid: INAP, págs. 233 y ss.; S. Díaz Sastre (2012), La tutela de los licitadores en la adjudicación de contratos públicos, Madrid: Marcial Pons, págs. 119 y ss., y J. M. Gimeno Feliú (2014), El nuevo paquete legislativo comunitario..., op. cit., págs. 196 y ss.

32 El concepto de pyme debe entenderse en el sentido de la definición de la Recomendación 2003/361/CE de la Comisión, de 6 de mayo de 2003, sobre la definición de microempresas, pequeńas y medianas empresas (DO L 124 de 20 de mayo de 2003, pág. 36). 
la legislación de la Unión en materia de contratación pública, con el fin de ayudar a los poderes adjudicadores y a los operadores económicos, en especial las pymes, a aplicar correctamente las normas sobre contratación pública de la Unión, y que se facilite apoyo a los poderes adjudicadores para ayudarles a planificar y llevar a cabo procedimientos de contratación.

Por lo que se refiere a la información estadística, la directiva exige que antes del 18 de abril de 2017, y posteriormente cada tres años, los Estados miembros remitan a la Comisión un informe estadístico sobre los contratos públicos sujetos a los umbrales comunitarios, haciendo una estimación del valor agregado total de dichos contratos durante el período de que se trate. Esa estimación podrá basarse, en particular, en los datos disponibles en virtud de los requisitos de publicación nacionales, o bien en estimaciones realizadas a partir de muestras.

Este informe podrá incluirse en el informe de supervisión que prevé la Directiva en su art. 83, apdo. 3.

Los Estados miembros también pondrán a disposición de la Comisión, en el informe de supervisión o en otro específico, información sobre su organización institucional adoptada para la transposición de la Directiva 2014/24, la supervisión y el cumplimiento de lo dispuesto en ella, así como sobre las iniciativas nacionales adoptadas para proporcionar orientación o ayuda en la aplicación de las normas de la Unión en materia de contratación pública, o para responder a las dificultades que plantee la aplicación de esas normas.

En el derecho español, el apdo. 13 del art. 332 de la nueva LCSP 2017 prevé que la Oficina Independiente de Regulación y Supervisión de la Contratación, en coordinación con el Ministerio de Hacienda y Función Pública y la Junta Consultiva de Contratación Pública del Estado, colaborará con las instituciones y organismos de la Unión Europea, en especial con la Comisión Europea, en el ejercicio de las funciones de regulación y supervisión de la contratación. También podrá cooperar con las autoridades de supervisión de la contratación independientes de otros Estados miembros.

El control de las licitaciones públicas va a verse reforzado también por la Oficina Nacional de Evaluación (ONE), un órgano colegiado creado por la Ley 40/2015, de 1 de octubre, de régimen jurídico del sector público ${ }^{33}$ e

33 El Gobierno no ha llegado a aprobar el Proyecto de Orden Ministerial por la que se determina la composición, organización y funcionamiento de la Oficina Nacional de Evaluación, para el cual la Ley 40/2015 (disposición final decimoctava) daba un plazo de seis meses y llegó a tramitarse hasta la información pública, que finalizó el 24 de junio de 2016. La LCSP de 2017 prevé ahora en el apdo. 2 de su art. 333, que mediante Orden del Ministro de Hacienda y Función Pública, a propuesta de la Oficina Independiente de Regulación y Supervisión de la Contratación, previo informe 
incorporado al TRLCSP como disposición adicional $36^{34}$ y a la LCSP 2017 en el art. 333, que lo integra en la nueva Oficina Independiente de Regulación y Supervisión de la Contratación.

La finalidad de la ONE es analizar la sostenibilidad financiera de los contratos de concesiones de obras y los contratos de concesión de servicios de los poderes adjudicadores y entidades adjudicadoras, así como por otros entes, organismos y entidades dependientes de la Administración General del Estado y de las Corporaciones Locales ${ }^{35}$; y de esta forma mejorar la eficiencia en la asignación y utilización de los recursos públicos, de acuerdo con lo dispuesto por la Ley Orgánica 2/2012, de 27 de abril, de Estabilidad Presupuestaria y Sostenibilidad Financiera.

La LCSP 2017 refuerza su independencia al establecer que los miembros de la ONE y el personal a su servicio no podrán, en el ejercicio de sus funciones, solicitar ni aceptar instrucciones de ninguna entidad pública o privada (último párrafo del apdo. 2 del art. 333).

Si la Administración o la entidad destinataria de los informes preceptivos de la ONE se apartara de las recomendaciones contenidas en los mismos, deberá motivarlo en un informe que se incorporará al expediente del correspondiente contrato y que será objeto de publicación en su perfil de contratante y en la Plataforma de Contratación del Sector Público.

\subsection{Deberes de los poderes adjudicadores}

La normativa europea impone ahora nuevas obligaciones a los poderes adjudicadores para garantizar la transparencia en la contratación pública.

Como destaca la exposición de motivos de la Directiva 2014/24, la trazabilidad y transparencia de la toma de decisiones en los procedimientos de

de la Comisión Delegada del Gobierno para Asuntos Económicos, «se determinará la organización y funcionamiento de la misma, sin perjuicio de la utilización de medios especializados complementarios que sean aportados por los órganos representados en la Oficina Nacional de Evaluación».

34 Esta norma aclaró su ámbito objetivo al limitarlo a las concesiones de obras y de servicios, como recoge ahora la nueva LCSP 2017. Véase al respecto X. Lazo Victoria (2015), «La Oficina Nacional de Evaluación: un control reforzado para las licitaciones públicas de la Administración General del Estado y de las Entidades Locales», Observatorio de Contratación Pública, http://www.obcp.es/index.php/mod.opiniones/ mem.detalle/id.214/relcategoria.208/relmenu.3/chk.37351ec9ddc005b73e5a5a508 6265e28 (consultado el 24 de febrero de 2017).

35 Las comunidades autónomas podrán adherirse a la ONE o crear organismos equivalentes. 
contratación es fundamental para garantizar unos procedimientos adecuados, incluida la lucha eficaz contra la corrupción y el fraude (apdo. 126) ${ }^{36}$.

Por ello, a fin de poder facilitar el acceso a los documentos de las partes interesadas, de conformidad con las normas aplicables en la materia, prevé la directiva que los poderes adjudicadores guarden copias de los principales contratos que celebren y documenten los elementos y decisiones esenciales de cada procedimiento de contratación. El informe que elaboren a tal efecto, para evitar cargas administrativas, podrá referirse a la información ya contenida en el correspondiente anuncio de adjudicación de contrato.

$\mathrm{El}$ art. 83.6 prevé la débil exigencia de que los poderes adjudicadores conserven, como mínimo durante la vigencia de cada contrato, copias de todos los contratos celebrados que sean de un valor igual o superior a 1000000 de euros, en el caso de los contratos públicos de suministro o de servicios, y a 10000000 de euros, en el caso de los contratos públicos de obras.

Los poderes adjudicadores garantizarán el acceso a dichos contratos; sin embargo, el acceso a determinados documentos o datos podrá ser denegado en la medida y en las condiciones establecidas en las normas nacionales o de la Unión aplicables sobre el acceso a los documentos y la protección de datos.

Por su parte, el art. 84 de la Directiva impone a los poderes adjudicadores la realización de informes específicos sobre cada contrato o acuerdo marco ${ }^{37}$ sujeto a regulación armonizada y cada vez que establezcan un sistema dinámico de adquisición, que incluyan los datos principales del contrato, como los resultados de la selección cualitativa, el adjudicatario y los motivos por los que se ha elegido su oferta, y los conflictos de intereses detectados y las medidas tomadas al respecto ${ }^{38}$.

Los poderes adjudicadores deberán documentar el desarrollo de todos los procedimientos de contratación y asegurarse de que conservan suficiente documentación para justificar las decisiones adoptadas en todas las etapas del procedimiento de contratación, como la documentación relativa a las co-

36 Véase, en general, T. Medina Arnáiz (2016), "La necesidad de reformar la legislación sobre contratación pública para luchar contra la corrupción: las obligaciones que nos llegan desde Europa», en Revista Vasca de Administración Pública, 104, págs. 77-113.

37 Dicho informe no será exigido por lo que respecta a contratos basados en acuerdos marco, cuando estos se hayan celebrado con arreglo al art. 33, apdo. 3 o apdo. 4, letra a) de la Directiva 2014/24.

38 Ahora bien, en la medida en que el anuncio de adjudicación de contrato redactado con arreglo a lo dispuesto en el art. 50 o en el art. 75, apdo. 2, contenga esta información requerida en este apdo. 1 del art. 84 (todos ellos preceptos de la Directiva 2014/24), los poderes adjudicadores podrán hacer referencia a dicho anuncio. 
municaciones con los operadores económicos y las deliberaciones internas, la preparación de los pliegos de la contratación, el diálogo o la negociación, en su caso, la selección y la adjudicación del contrato. La documentación deberá conservarse como mínimo durante un período de tres años a partir de la fecha de adjudicación del contrato.

Este informe, o sus elementos principales, se transmitirán a la Comisión o a las autoridades, organismos o estructuras nacionales competentes, contemplados en el artículo 83 de la Directiva, pero solo cuando estos lo soliciten.

1.3. La lamentable carencia de estadísticas sobre contratación pública en la Unión Europea y en España

La Directiva 2014/24 prevé que la Comisión europea analizará la calidad y la integridad de los datos que puedan extraerse de los diversos anuncios a realizar de los procedimientos de contratación pública ${ }^{39} \mathrm{y}$, cuando no se ajuste a las obligaciones estipuladas la propia norma, solicitará información complementaria a los Estados miembros de que se trate.

El problema de la falta de suficientes estadísticas sobre los contratos administrativos afecta en la actualidad de forma grave a la Unión Europea. Por desgracia, nada tiene que ver la información relacionada con este sector de las compras públicas con las completas estadísticas de carácter macroeconómico que ofrece la Oficina Europea de Estadística ${ }^{40}$ (que sirven para apoyar las decisiones del Banco Central Europeo en su política monetaria para el euro), sus datos regionales y clasificación (NUTS) que orientan las políticas estructurales de la Unión Europea, las relativas al sector económico privado, a la industria, el comercio y servicios, la agricultura y pesca o el comercio exterior ${ }^{41}$.

La Resolución del Parlamento Europeo de 20 de junio de 2007, sobre problemas específicos de transposición y aplicación de la legislación relativa a la contratación pública ${ }^{42}$, ya advirtió de la existencia de problemas en Europa en cuanto a la recogida de datos sobre la contratación pública que obedecían, a su entender, a la existencia de numerosas autoridades adjudicadoras en los distintos países y al hecho de que la lista de casos en los que las normas no se han aplicado correctamente es amplia.

39 Los anuncios están previstos en los arts. 48, 49, 50, 75 y 79 de la Directiva 2014/24 y deben publicarse de conformidad con el anexo VIII de la misma.

40 Véase la web http://ec.europa.eu/eurostat, fecha de consulta 3 de enero de 2017.

41 M. Bohata, M. Hahn, A. Baigorri y G. L. Mazzi (2012), «Towards a Eurostat Framework for Disseminating Innovative/Experimental Statistics», en Estadistica española, 54, 178, págs. 197 y ss.

42 Documento A6-0226/2007. 
En España, la Ley 19/2013, de 9 de diciembre, de transparencia, acceso a la información pública y buen gobierno, obligó en su art. 8 a que las administraciones, entidades y organismos públicos hagan públicos en sus portales de contratación sobre:

[...] todos los contratos, con indicación del objeto, duración, el importe de licitación y de adjudicación, el procedimiento utilizado para su celebración, los instrumentos a través de los que, en su caso, se ha publicitado, el número de licitadores participantes en el procedimiento y la identidad del adjudicatario, así como las modificaciones del contrato. Igualmente, serán objeto de publicación las decisiones de desistimiento y renuncia de los contratos. La publicación de la información relativa a los contratos menores podrá realizarse trimestralmente.

Asimismo, obligó a publicar datos estadísticos sobre el porcentaje en volumen presupuestario de contratos adjudicados a través de cada uno de los procedimientos previstos en la legislación de contratos del sector público.

La Ley 20/2013, de 9 de diciembre, de garantía de la unidad de mercado, introdujo la tan importante ${ }^{43}$ como incumplida ${ }^{44}$ obligación de publicar en la Plataforma de Contratos del Sector Público toda licitación pública de cualquier poder adjudicador, sea o no estatal.

El 16 de diciembre de 2016, el Consejo de Ministros aprobó unas instrucciones para el sector público estatal con la finalidad de incrementar la transparencia y la publicidad en el ámbito de la contratación pública, al establecer más obligaciones de publicar electrónicamente en la Plataforma de Contratación del Sector Público ${ }^{45}$, incluyendo los procedimientos negociados sin publicidad por razón de la cuantía.

43 J. M. Gimeno Feliú (2016), «La obligación de publicidad de todas las licitaciones en la plataforma de contratos del sector público. Hacia una efectiva política de transparencia», http://www.obcp.es/index.php/mod.opiniones/mem.detalle/id.153/relcategoria.121/relmenu.3/chk.577429fa7149b11b2d930ebe5b579d9f (consultado el 4 de enero de 2017). Resultan muy ilustrativos al respecto los estudios realizados en 2016 por Transparencia Internacional Espańa y el Observatorio de Contratación Pública sobre el nivel de cumplimiento por parte de las instituciones públicas españolas de la obligación legal de publicar sus contratos y licitaciones en la Plataforma de Contratación del Sector Público. De los 110 grandes ayuntamientos españoles analizados, solo el $30 \%$ cumple la legislación vigente al respecto, mientras que solo 6 de las 17 comunidades autónomas respetan esta normativa (http://transparencia.org.es/las-instituciones-publicascontinuan-incumpliendo-mayoritariamente-la-normativa-legal-sobre-contratos/ consultado el 4 de enero de 2017).

45 Resolución de 19 de diciembre de 2016, de la Dirección General del Patrimonio del Estado, que publica el Acuerdo del Consejo de Ministros de 16 de diciembre de 2016, 


\section{DISEÑO DE POLÍTICAS ESTRATÉGICAS}

De acuerdo con el apdo. 3 del art. 83 de la Directiva 2014/24, la Comisión podrá pedir a los Estados miembros, cada tres años como máximo, que le faciliten información sobre la aplicación práctica de las políticas estratégicas de contratación nacionales.

La Comisión publicará, sobre la base de los datos recibidos en virtud del citado precepto, un informe periódico sobre la aplicación de las políticas nacionales de contratación en el mercado interior y las prácticas más idóneas en ese contexto.

Resulta evidente que todavía queda mucho por mejorar en la aplicación de la normativa de la Unión Europea en materia de contratación pública, como prueban tanto el debate y las conclusiones del Libro Verde de la Comisión Europea sobre la modernización de la política de contratación pública de la $\mathrm{UE}^{46}$, como los propios trabajos preparatorios de las Directivas 23, 24 y 25 de 2014. Una de las mayores debilidades del sistema europeo de contratos públicos consiste en la carencia de una perspectiva global de los posibles problemas estructurales y modelos generales en las diferentes políticas nacionales en materia de contratación, a fin de hacer frente a posibles problemas de forma más selectiva ${ }^{47}$.

Acierta la exposición de motivos de la Directiva 2014/24 al advertir que esta visión de conjunto:

[...] debe obtenerse a través de un seguimiento adecuado, cuyos resultados han de publicarse con regularidad, a fin de posibilitar un debate informado sobre la introducción de posibles mejoras en las normas y la práctica en materia de contratación (apdo. 121).

También resulta imprescindible una mejor orientación, información y asistencia a los poderes adjudicadores y los agentes económicos, lo que contribuiría a hacer más eficiente la contratación pública, gracias a mejores conocimientos, a una mayor seguridad jurídica y a la profesionalización de las

por el que se instruye a las entidades del sector público estatal para dar publicidad a determinados contratos no sujetos a regulación armonizada.

Libro Verde «sobre la modernización de la política de contratación pública de la UE. Hacia un mercado europeo de la contratación pública más eficiente», de 27 de enero de 2011 (COM 2011, 15 final).

47 Pueden verse al respecto las respuestas a las consultas del Libro Verde dadas por los investigadores del Proyecto financiado por el Ministerio de Ciencia e Innovación (DER JURI 2009-12116), recogidas en la obra colectiva (2011) Observatorio de contratos públicos 2010, Cizur Menor: Civitas-Thomson Reuters, págs. 459 y ss. 
prácticas de contratación. Sería de especial importancia dicha orientación en aspectos como la planificación de las adquisiciones, los procedimientos, la elección de técnicas e instrumentos y las buenas prácticas para tramitar los procedimientos ${ }^{48}$, y así poder aprovechar plenamente las posibilidades que ofrecen los contratos para alcanzar los objetivos fijados en la Estrategia Europa 2020: la contratación en materia medioambiental, social y de innovación ${ }^{49}$.

La Recomendación de Decisión del Consejo de la Unión Europea de 27 de julio de 2016, por la que formula una advertencia a España para que adopte medidas dirigidas a la reducción del déficit que se considera necesaria para poner remedio a la situación de déficit excesivo ${ }^{50}$, subraya que:

España también debe prestar la debida atención a los aspectos cualitativos de las finanzas públicas, incluida su política de contratación pública. Ha sido significativo el número de irregularidades con un impacto en la aplicación de la legislación sobre contratación pública de la UE puesto en conocimiento de la Comisión durante los últimos años. Los datos ponen de manifiesto que existen divergencias en la ejecución de los contratos públicos en las entidades y autoridades de contratación y que la falta de mecanismos de control a priori y a posteriori suficientes obstaculiza la aplicación correcta y uniforme de la legislación en materia de contratación pública (considerando 14).

El Informe de la Comisión Nacional de los Mercados y la Competencia (CNMC), "Análisis de la contratación pública en España: oportunidades de mejora desde el punto de vista de la competencia ${ }^{51}$, estima que la existencia de prácticas irregulares desde el punto de vista de la competencia en la contratación pública puede originar desviaciones medias, al alza, del $25 \%$ del presupuesto de la contratación pública. En España, a nivel agregado, esto podría implicar hasta un 4,6\% del PIB anual, aproximadamente 47500 millones de euros/año ${ }^{52}$.

Hay que recordar que, según datos de la Comisión Europea, las compras de las administraciones públicas y de sus organismos dependientes suponen

48 OCDE (2009), La integridad en la Contratación Pública. Buenas prácticas de la $A$ a la $Z$ (trad. I. Sánchez Gil), Madrid: Instituto Nacional de Administración Pública, págs. 19 y ss.

49 J. M. Gimeno Feliú (2016), «El nuevo paquete legislativo comunitario de contratación pública: principales novedades. La orientación estratégica de la contratación pública», en AA.VV. (S. Rodríguez Campos, coord.), Las nuevas directivas de contratos públicos y su trasposición, Madrid: Marcial Pons, pág. 16.

50 Documento SWD (2016), 263 final.

51 Informe PRO/CNMC/001/15, de 5 de febrero de 2015.

52 Página 6 del Informe PRO/CNMC/001/15, cit., a través del cual la CNMC expone su voluntad de colaborar con las autoridades públicas para asegurar la máxima tensión competitiva posible antes, durante y después de cada contratación pública. 
más del 19\% del Producto Interior Bruto de la Unión Europea ${ }^{53}$, aproximadamente 2500000000 euros.

En España supone aproximadamente el 18,5\% del PIB ${ }^{54}$, esto es, alrededor de 194000 millones de euros anuales o más de 4100 euros anuales per cápita $^{55}$. Como destaca la CNMC, tanto la sanidad como la educación, la justicia, la seguridad pública o el transporte se ven afectados profundamente por el qué, el cómo, el cuánto, el cuándo y el por quién se aprovisiona de bienes y servicios el sector público, en todas sus dimensiones territoriales y formas jurídicas ${ }^{56}$.

A nivel mundial, el peso de la contratación pública se situaría entre un 13 y un $20 \%$ del PIB, como reflejan las estadísticas de la Organización para la Cooperación y el Desarrollo Económico (OCDE) ${ }^{57}$.

\section{PUNTO DE CONTACTO ÚNICO DE ESPAÑA: LA JUNTA CONSULTIVA DE CONTRATACIÓN PÚBLICA DEL ESTADO}

El apdo. 5 del art. 83 de la Directiva 2014/24 obliga a los Estados a designar «un punto de referencia para la cooperación con la Comisión en lo que se refiere a la aplicación de la legislación relativa a la contratación pública».

Este punto de contacto funcionaría como una ventanilla única para las cuestiones referentes a la contratación pública en cada Estado miembro ${ }^{58}$.

A nivel comunitario, ya existen una serie de procedimientos y métodos de trabajo en relación con las comunicaciones de la Comisión y sus contactos con los Estados miembros: los previstos en los arts. 258 y 260 del TFUE, como la Red de Resoluciones de Problemas en el Mercado Interior (SOLVIT) ${ }^{59}$ y

53 Véase el documento «Evaluation Report Impact and Effectiveness of EU Public Procurement Legislation», http://ec.europa.eu/growth/single-market/public-procurement/ modernising-rules/evaluation/index_en.htm (consultado el 2 de febrero de 2017).

54 Observatorio de Contratación Pública, www.obcp.es, consultado el 5 de febrero de 2017.

55 De acuerdo con los datos del INE (www.ine.es, fecha de consulta 25 de febrero de 2017) para 2013, el PIB nominal fue de 1049181 millones de euros y la población de 46,46 millones de habitantes.

56 Informe PRO/CNMC/001/15, cit., pág. 3.

57 OCDE (2016), «Public Procurement for Sustainable and Inclusive Growth. Enabling Reform through Evidence and Peer Reviews», http://www.oecd.org/gov/ethics/PublicProcurementRev9.pdf (consultado el 20 de enero de 2017).

58 Exposición de motivos de la Directiva 2014/24, apdo. 125.

59 SOLVIT es un servicio gratuito de las administraciones nacionales de los países de la UE, Islandia, Liechtenstein y Noruega, que se presta principalmente online y se creó a raíz de la Recomendación 2001/893/CE de la Comisión, de 7 de diciembre de 2001 
EU Pilot ${ }^{60}$, sobre los que no se introducen modificaciones por la Directiva 2014/24.

No obstante, esta norma va más allá al prever la designación de un punto de referencia único en cada Estado miembro para la cooperación con la Comisión.

En España, la proposición de ley de medidas para promover la transparencia en la contratación pública ${ }^{61}$, adelantándose a la regulación prevista en el proyecto de nueva ley de contratos del sector público, planteó la atribución a la Junta Consultiva de Contratación Administrativa del Estado de la condición de punto de referencia único para el Estado español y, asimismo, la creación en el seno de la misma del Comité de Cooperación en materia de contratación pública.

Hay que resaltar en este sentido cómo la Recomendación de Decisión del Consejo de la Unión Europea, de 27 de julio de 2016 ${ }^{62}$, advierte de la carencia en España de un organismo independiente encargado de garantizar la eficacia y el cumplimiento de la legislación en materia de contratación pública, lo que también ha llevado a la Comisión Europea, en su Informe España $2017^{63}$, a cuestionar la ausencia de una política de contratación pública a nivel nacional que garantice la competencia y la transparencia.

La LCSP 2017, en el art. 328, tras definir la Junta Consultiva de Contratación Pública del Estado (JCCPE) como el órgano específico de regulación y consulta en materia de contratación pública del sector público estatal, adscrito al Ministerio de Hacienda y Función Pública, establece como funciones, en todo caso, de la misma promover la adopción de las normas o medidas de carácter general que considere procedentes para la mejora del sistema de

(C 2001, 3901). Véase también al respecto la Recomendación de la Comisión sobre los principios por los que se rige SOLVIT (C 2013, 5869 final) y la Comunicación de la Comisión sobre la resolución eficaz de problemas en el mercado interior (COM 2001, 702 final).

60 La idea del proyecto EU Pilot se lanzó en la Comunicación de la Comisión de 2007 «Una Europa de resultados» (COM 2007, 502), que destaca que el objetivo de EU Pilot es atender las solicitudes de información y denuncias de los ciudadanos y las empresas que se refieran a la aplicación correcta del derecho de la UE. Véase http:// ec.europa.eu/internal_market/scoreboard/performance_by_governance_tool/eu_pilot/index_en.htm, consultado el 22 de diciembre de 2016.

61 Publicada en el Boletín Oficial de las Cortes Generales, Serie B no 52-1, de 21 de octubre de 2016.

62 Documento citado, SWD (2016), 263 final.

63 Documento de trabajo de los servicios de la Comisión, «Informe del país España 2017» (SWD 2017, 74 final, de 22 de febrero de 2017). 
contratación en sus aspectos administrativos, técnicos y económicos; aprobar recomendaciones generales o particulares a los órganos de contratación; informar sobre las cuestiones que se sometan a su consideración y, con carácter preceptivo, sobre todas las disposiciones normativas de rango legal y reglamentario en materia de contratación pública de competencia estatal; y coordinar el cumplimiento de las obligaciones de información que imponen las directivas de contratación.

En este sentido, la JCCPE elaborará y remitirá a la Comisión Europea cada tres ańos un informe ${ }^{64}$ referido a todos los poderes adjudicadores estatales, autonómicos y locales que, respecto de la licitación pública y ejecución de los contratos de obras, suministros, servicios, concesión de obras y concesión de servicios que estén sujetos a regulación armonizada, comprenda la información contenida en el informe de supervisión del apdo. 7 del art. 332 LCSP 2017 que remita la Oficina Independiente de Regulación y Supervisión de la Contratación; la información sobre el nivel de participación de las pymes en la contratación pública; un informe estadístico sobre los contratos públicos de obras, suministros y servicios no sujetos a regulación armonizada; información sobre cuáles son los órganos encargados de dar cumplimiento a las obligaciones asumidas en virtud del derecho de la Unión Europea en materia de la contratación pública; e información sobre las iniciativas adoptadas para proporcionar orientación o ayuda gratuita en la aplicación de la normativa de la Unión Europea en materia de contratación pública o para dar respuesta a las dificultades que plantee su aplicación, así como para planificar y llevar a cabo procedimientos de contratación.

A todos los efectos, la nueva Ley de contratos designa a la JCCPE como punto de referencia para la cooperación con la Comisión Europea en lo que se refiere a la aplicación de la legislación relativa a la contratación pública. Asimismo, se encargará de prestar asistencia recíproca y de cooperar con el resto de Estados miembros de la Unión Europea, con el fin de garantizar el intercambio de información sobre las cuestiones que se establecen en la normativa comunitaria, garantizando su confidencialidad (apdo. 5 del art. 328 de la LCSP de 2017).

64 La JCCPE hará público el contenido de los informes nacionales en el plazo de un mes a contar desde su remisión a la Comisión Europea, publicándolos en los portales de transparencia y en la Plataforma de Contratación del Sector Público. Véase al respecto M. M. Razquin Lizárraga (2016), «Transposición de las nuevas directivas de contratación pública: similitudes y diferencias respecto del marco jurídico vigente en España", en AA.VV. (S. Rodríguez Campos, coord.), Las nuevas directivas de contratos públicos y su trasposición, Madrid: Marcial Pons, pág. 161. 


\section{EL COMITÉ DE COOPERACIÓN EN MATERIA DE CONTRATACIÓN PÚBLICA Y SU COMPETENCIA PARA LA ELABORACIÓN DE LA PROPUESTA DE ESTRATEGIA NACIONAL DE CONTRATACIÓN PÚBLICA}

El art. 329 de la nueva Ley de contratos del sector público contempla la creación del Comité de cooperación en materia de contratación pública, insertado en el seno de la JCCPE ${ }^{65}$, que servirá para articular un espacio de coordinación y cooperación en áreas de acción común con las comunidades autónomas y con las entidades locales.

En este sentido, el pleno del Comité será presidido por el director general del Patrimonio del Estado del Ministerio de Hacienda y Función Pública, y lo integrarán tanto representantes de la Administración General del Estado ${ }^{66}$ como de las comunidades y ciudades autónomas ${ }^{67}$, así como de las organizaciones representativas de las entidades locales ${ }^{68}$.

Le corresponderá al Comité coordinar los criterios de interpretación seguidos por las administraciones públicas en relación con las normas de la contratación pública y proponer los criterios de selección de actuaciones de supervisión de la contratación, así como elaborar una metodología básica común para las mismas y analizar las cuestiones relativas a la contratación pública que resulten de interés común.

También supervisará el funcionamiento de la Plataforma de Contratación del Sector Público y del Registro Oficial de Licitadores y Empresas Clasificadas del Sector Público.

65 De acuerdo con el apdo. 7 del art. 329 de la LCSP, el funcionamiento del comité de cooperación será atendido con los medios personales, técnicos y presupuestarios asignados a la JCCPE.

66 De la Administración General del Estado se nombrarán cinco vocales en representación de la Intervención General de la Administración del Estado, de la Abogacía General del Estado, de la Dirección General de Racionalización y Centralización de la Contratación del Ministerio de Hacienda y Función Pública y de la Dirección General de Coordinación de Competencias con las Comunidades Autónomas y Entidades Locales del Ministerio de Presidencia y para las Administraciones Territoriales; así como el titular del órgano de apoyo técnico de la JCCPE al que correspondan las materias referidas en el apdo. 4 del art. 325 de la LCSP. Formará parte asimismo, como vocal nato, el presidente de la oficina independiente de regulación y supervisión de la contratación (art. 329.2.a) de la LCSP).

67 Por parte de las comunidades autónomas y de las ciudades autónomas de Ceuta y Melilla, integrará el Pleno un representante designado por cada una de ellas (art. 329.2.b) de la LCSP).

68 Las entidades locales estarán representadas en el comité por un representante de la asociación o federación de entidades locales con mayor implantación (art. 329.2.c) de la LCSP). 
El Comité de cooperación en materia de contratación pública será, asimismo, el encargado de recopilar la información a remitir a la Comisión Europea cada tres años, que exige la Directiva 2014/24 y recoge el art. 328 de la nueva Ley de contratos, a cuyo efecto podrá establecer las instrucciones necesarias, y pondrá la información a disposición de la JCCPE.

Pero como función de más relevancia se le atribuye al Comité la elaboración de la propuesta de Estrategia Nacional de supervisión, que corresponderá aprobar a la Oficina Independiente de Regulación y Supervisión de la Contratación.

La Estrategia Nacional de Contratación Pública es el instrumento jurídico vinculante, aprobado por la Oficina Independiente de Regulación y Supervisión de la Contratación, que se basará, con un horizonte temporal de cuatro años, en el análisis de actuaciones de contratación realizadas por todo el sector público, incluyendo todos los poderes adjudicadores y entidades adjudicadoras comprendidas en el sector público estatal, autonómico o local, así como las de otros entes, organismos y entidades pertenecientes a los mismos que no tengan la naturaleza de poderes adjudicadores.

La Estrategia Nacional tendrá como objetivos, todos ellos planteados por la cuarta generación de directivas sobre contratación pública ${ }^{69}$, combatir la corrupción y las irregularidades en la aplicación de la legislación sobre contratación pública, incrementar la profesionalización de los agentes públicos que participan en los procesos de contratación y promover la eficiencia económica en los procesos de obtención de bienes, servicios y suministros para el sector público, estimulando la agregación de la demanda y la adecuada utilización de criterios de adjudicación. También perseguirá generalizar el uso de la contratación electrónica en todas las fases del procedimiento; utilizar las posibilidades de la contratación pública para apoyar políticas ambientales, sociales y de innovación, y promover la participación de las pymes, en el mercado de la contratación pública.

El art. 334 contempla como cuestiones a abordar por la Estrategia, en primer lugar, el análisis de los datos disponibles, en las distintas fuentes de información cualitativas y cuantitativas: plataformas de contratación nacionales, información abierta de la Unión Europea en materia de contratación pública (la versión online del Suplemento del Diario Oficial de la Unión Europea dedicado a la contratación pública europea ${ }^{70}$ ), informes de órganos de supervisión y control y de asesoramiento legal, para elaborar un diagnóstico de la situación de la contratación pública y proponer medidas prioritarias para la corrección de las disfunciones que se identifiquen.

69 Puede verse al respecto J. M. Gimeno Feliú (2014), El nuevo paquete legislativo comunitario, op. cit., págs. 25 y ss.

70 Disponible en la web ted.europe.eu (consultada el 4 de octubre de 2017). 
A tales efectos, las indicadas bases de datos nacionales y los correspondientes órganos de supervisión, control y asesoramiento deberán facilitar la información necesaria para la elaboración, aprobación y ejecución de la mencionada Estrategia.

También abordará la Estrategia la mejora de la supervisión de la contratación pública, coordinando criterios y metodologías comunes para la realización de las actuaciones de supervisión, y garantizando, en todo caso, el cumplimiento de las obligaciones de supervisión impuestas por las Directivas de contratación pública y por las instituciones comunitarias.

Contemplará, asimismo, la coherencia de las actuaciones de seguimiento precisas para garantizar la sostenibilidad financiera de los contratos previstos por el art. 334, para lo que incluirá las estrategias y metodología adecuada para realizar la evaluación con criterios homogéneos y las reglas que deben informar los acuerdos de establecimiento del equilibrio económico de estos contratos.

Por otra parte, analizará de los mecanismos de control de legalidad ex ante y ex post de los procedimientos de adjudicación de contratos públicos y concesiones en todo el sector público. Se preverán actuaciones con vistas a reforzar dichos mecanismos de control, entre otras, mediante la definición de objetivos y prioridades, así como la propuesta de reasignación de efectivos encargados de dichos controles. Igualmente, se analizarán los procedimientos establecidos para identificar las irregularidades en las que se pudiera incurrir y el desarrollo de las medidas correctoras que deban aplicarse por los responsables de la gestión ${ }^{71}$.

La Estrategia podrá prever la elaboración de manuales de buenas prácticas o guías que establezcan recomendaciones para aplicar en los procedimientos de contratación, que permitan preventivamente evitar la posible realización de malas prácticas en los mismos.

Como otro aspecto importante de la Estrategia, promoverá la profesionalización en contratación pública ${ }^{72}$, mediante actuaciones de formación del personal del sector público, especialmente en aquellas entidades que carecen de personal especializado, mediante el diseño de un plan específico en materia

71 Los funcionarios que realicen estas funciones de supervisión gozarán de independencia funcional respecto de los titulares de los órganos cuyos contratos supervisen, como prevé el apdo. 3 del art. 332 de la LCSP, que también contempla la obligación de las autoridades, los jefes o directores de oficinas públicas, los de las entidades integrantes del sector público y quienes, en general, ejerzan funciones públicas o desarrollen su trabajo en dichas entidades, de prestar a los funcionarios encargados de la supervisión de los contratos el apoyo, concurso, auxilio y colaboración que les sean precisos, facilitando la documentación e información necesaria para dicha supervisión. Acerca de la importancia de la misma puede verse el trabajo E. Malaret (2016), «El nuevo reto de la contratación pública para afianzar la integridad y el control: reforzar el profesionalismo y la transparencia», en Revista digital de Derecho Administrativo, 15, págs. 21 y ss. 
de formación en contratación pública y otras actuaciones complementarias de promoción de la profesionalización en la contratación pública.

\section{LA OFICINA INDEPENDIENTE DE REGULACIÓN Y SUPERVISIÓN DE LA CONTRATACIÓN COMO PILAR DEL NUEVO SISTEMA DE GOBERNANZA EN EL ORDENAMIENTO JURÍDICO ESPAÑOL}

El art. 332 de la nueva LCSP crea la Oficina Independiente de la Regulación y Supervisión de la Contratación ${ }^{73}$ (hubiera sido más correcto técnicamente que en su denominación se precisara la referencia a la contratación como pública) con la finalidad de velar por la correcta aplicación de la legislación y, en particular, promover la concurrencia y combatir las ilegalidades, en relación con la contratación pública. La Oficina actuará en el desarrollo de su actividad y el cumplimiento de sus fines con plena independencia orgánica y funcional, lo que permite superar las carencias iniciales tanto del anteproyecto como del proyecto de $\mathrm{LCSP}^{74}$, que atribuían las funciones de supervisión de la contratación a la Junta Consultiva de Contratación Pública del Estado, un órgano dependiente del Ministerio de Hacienda y Función Pública.

Se trata de una de las principales reivindicaciones del Grupo Parlamentario de Ciudadanos ${ }^{75}$ en la tramitación del proyecto de $\mathrm{LCSP}^{76}$.

73 Como órgano colegiado de los previstos en el art. 19 de la Ley 40/2015, de 1 de octubre, de Régimen Jurídico del Sector Público.

74 Un análisis crítico del proyecto de LCSP en este sentido se puede encontrar en D. Canals Ametller, «La supervisión del cumplimiento y aplicación de la normativa europea de contratos públicos», en el blog de la Revista Catalana de Dret Public, https://eapcrcdp.blog.gencat.cat/2017/06/07/la-supervision-del-cumplimiento-y-aplicacion-dela-normativa-europea-de-contratos-publicos-dolors-canals-ametller/?ct=t, consultado el 7 de junio de 2017. La Comisión Nacional de los Mercados y la Competencia había propuesto la atribución de estas funciones de control a una autoridad independiente en su «Informe sobre el Anteproyecto de Ley de Contratos del Sector Público», IPN/CNMC/010/15, de 16 de julio de 2015, apdo. IV, pág. 12.

75 «Órdago de Ciudadanos para que se cree un supervisor de la obra pública en la CNMC», titulaba la información El Confidencial: http://www.elconfidencial.com/ empresas/2017-04-03/c-s-aprovecha-la-nueva-ley-de-contratos-para-dar-a-la-cnmc-el-control-sobre-la-obra-publica_1359198/ (fecha de consulta: 3 de abril de 2017). Puede verse también la noticia «PP y C`s negocian crear un supervisor de contratos públicos por la corrupción» en El Economista: http://www.eleconomista. es/economia/noticias/8390348/05/17/PP-y-Cs-negocian-crear-un-supervisor-decontratos-publicos-por-la-corrupcion.html, consultado el 14 de julio de 2017.

76 El texto del art. 332 (inicialmente el artículo 327 ter) se aprobó en el Congreso por la ponencia por mayoría, como consecuencia de la aceptación de la enmienda transaccional 
Con un contenido marcadamente reglamentario, característica común a muchos preceptos de la LCSP, el art. 332 de la norma detalla la formación de la Oficina Independiente, con un presidente y cuatro vocales ${ }^{77}$; su adscripción, a efectos puramente organizativos y presupuestarios, al Ministerio de Hacienda y Función Pública, a través de la Subsecretaría del Departamento; y la integración en la misma de la Oficina Nacional de Evaluación regulada en el art. 333 de la propia ley.

Todos los miembros de la Oficina Independiente serán designados por el Consejo de Ministros, a propuesta del ministro de Hacienda y Función Pública, por un periodo improrrogable de seis años ${ }^{78}$, y tendrán la condición de independientes e inamovibles durante el periodo de su mandato

En cuanto a las funciones de la Oficina Independiente de Regulación y Supervisión de la Contratación, le corresponde coordinar la supervisión en materia de contratación de los poderes adjudicadores del conjunto del sector público; velar por la correcta aplicación de la legislación de la contratación pública a los efectos de detectar incumplimientos específicos o problemas sistémicos y garantizar el respeto a los principios de publicidad y concurrencia y de las prerrogativas de la Administración en la contratación; promover la concurrencia en la contratación pública y el seguimiento de las buenas prácticas; verificar que se apliquen con la máxima amplitud las obligaciones y

procedente de las enmiendas 192 del GP Confederal de Unidos Podemos-En Comú Podem-En Marea y 414 del GP Ciudadanos. A su vez, el art. 333 (cuando se incluyó en el proyecto numerado como art. 327 quater), que regula la Oficina Nacional de Evaluación, fue aprobado por la ponencia por mayoría como consecuencia de la aceptación de la enmienda transaccional procedente de la enmienda 420 del GP Ciudadanos y el artículo 334 (327 quinquies), que disciplina la Estrategia Nacional de Supervisión, fue aprobado por mayoría al aceptarse la enmienda transaccional procedente de las enmiendas 414 del GP Ciudadanos y 1030 del GP Popular (véase el BOCG, serie A, núm. 2-4, de 2 de agosto de 2017).

77 Los titulares de la presidencia y de las vocalías de la Oficina Independiente de Regulación y Supervisión de la Contratación serán funcionarios de carrera pertenecientes al subgrupo A1 del art. 76 del Texto Refundido del Estatuto Básico del Empleado Público, aprobado por Real Decreto Legislativo 5/2015, de 30 de octubre, que cuenten, al menos, con diez años de experiencia profesional en materias relacionadas con la contratación pública. Durante el desempeño de sus cargos, estarán sujetos a la regulación prevista en los arts. 13, 14 y 15 de la Ley 3/2015, de 30 de marzo, reguladora del ejercicio del alto cargo en la Administración General del Estado.

78 No obstante, la primera renovación de la Oficina se hará de forma parcial a los tres años del nombramiento. Antes de cumplirse el plazo indicado se determinará, mediante sorteo, los dos vocales que deban cesar. Transcurrido este plazo, quedarán en funciones en tanto no se proceda al nombramiento de su sucesor (apdo. 3 del art. 332 de la LCSP). 
buenas prácticas de transparencia, en particular las relativas a los conflictos de intereses, y detectar las irregularidades que se produzcan en materia de contratación ${ }^{79}$.

El titular de la presidencia de la Oficina remitirá a las Cortes y al Tribunal de Cuentas un informe anual sobre las actuaciones de la Oficina y comparecerá en las Cortes para la presentación del informe anual y sus conclusiones, o cuando se solicite por las correspondientes Comisiones del Congreso o el Senado, en relación con los asuntos que formen parte de su ámbito funcional. Dicho informe será objeto de publicación dentro del mes siguiente a su remisión a las Cortes y al Tribunal de Cuentas.

En el caso de que la Oficina tenga conocimiento de hechos constitutivos de delito o infracción a nivel estatal, autonómico o local, dará traslado inmediato, en función de su naturaleza, a la fiscalía u órganos judiciales competentes, o a las entidades u órganos administrativos competentes, incluidos el Tribunal de Cuentas y la Comisión Nacional de los Mercados y la Competencia.

En ejercicio de sus funciones, la Oficina aprobará, a propuesta del Comité de Cooperación en materia de contratación pública, la Estrategia Nacional de Contratación Pública vinculante para el sector público prevista en el art. 334 de la LCSP 2017, que se diseñará y ejecutará en coordinación con las comunidades autónomas y entidades locales ${ }^{80}$. Una vez aprobada ${ }^{81}$, se remitirá a la Comisión Europea y el Consejo de Ministros, a propuesta del Ministerio de Hacienda y Función Pública, tomará conocimiento de la misma y la elevará para conocimiento a las Cortes Generales. Transcurrido un mes desde la remisión a la Comisión Europea, se hará público su contenido en la Plataforma de Contratación del Sector Público.

79 J. C. Gómez Guzmán propone que el organismo desarrolle también funciones de auditoría de contrato, así como de normalización y regulación de los criterios para la asignación de costes en los contratos públicos, en especial en la compra pública precomercial y en los modificados de los contratos que son adjudicados directamente al mismo tiempo que desarrolla el contrato principal («Funciones para el órgano independiente de supervisión de la contratación pública», http://www.obcp.es/index. $\mathrm{php} / \mathrm{mod} . o p i n i o n e s / \mathrm{mem}$.detalle/id.307/relmenu.3/chk.cf78aebfd331091f360e89895f9f511, fecha de consulta 25 de septiembre de 2017).

La letra a) del apdo. 1 del art. 334 LCSP 2017 prevé que la Comisión Nacional de los Mercados y la Competencia pueda remitir a la Oficina sus propuestas en materia de contratación pública que afecten a la competencia, para su posible inclusión en la Estrategia Nacional de Contratación Pública.

81 La primera Estrategia se aprobará por la Oficina Independiente en el plazo de nueve meses desde la publicación de la LCSP 2017 en el Boletín Oficial del Estado (apdo. 7 del art. 334 LCSP 2017). 
La Oficina también podrá remitir informes a las Cortes Generales o, en su caso, a la Comisión Nacional de los Mercados y la Competencia, y podrá aprobar instrucciones, que serán obligatorias para todos los órganos de contratación del sector público del Estado, fijando las pautas de interpretación y de aplicación de la legislación de la contratación pública, así como elaborar recomendaciones generales o particulares a los órganos de contratación, si de la supervisión desplegada se dedujese la conveniencia de solventar algún problema, obstáculo o circunstancia relevante a los efectos de dar satisfacción a los fines justificadores de la creación de la Oficina. Las instrucciones y las recomendaciones serán objeto de publicación.

La Oficina elaborará un informe de supervisión que remitirá a la Junta Consultiva de Contratación Pública del Estado, que se integrará en el informe nacional a remitir a la Comisión Europea cada tres años. El informe comprenderá, respecto de la licitación pública y ejecución de los contratos de obras, suministros, servicios, concesión de obras y concesión de servicios que estén sujetos a regulación armonizada:

a) Una relación de los principales incumplimientos detectados por los órganos, instituciones y poderes con competencia supervisora o jurisdiccional en materia de contratación pública.

b) Información sobre las fuentes más frecuentes de aplicación incorrecta de la legislación de contratación pública o de inseguridad jurídica.

c) Información sobre la prevención, detección y notificación adecuada de los casos de fraude, corrupción, conflicto de intereses y otras irregularidades graves en la contratación, así como sobre los problemas de colusión detectados (apdo. 8 del art. 332 LCSP 2017).

Asimismo, la Oficina elaborará un informe anual que recogerá las conclusiones derivadas de toda la actividad de supervisión realizada por las administraciones competentes. El informe incluirá una relación expresiva de los principales incumplimientos constatados y de los órganos responsables de los mismos. Dicho informe será remitido por la Oficina de Supervisión a la Comisión Europea, a través de la Junta Consultiva de Contratación Pública del Estado.

El alcance y la relevancia de las competencias atribuidas a la Oficina, así como su independencia, cuestionan la integración formal de su regulación en el capítulo III, referido a los órganos consultivos, del título I del libro IV de la nueva LCSP.

Estas funciones de supervisión se realizarán por la Oficina sin perjuicio de las competencias que corresponden a la Intervención General de la Administración del Estado, en cuanto órgano de control de la gestión económico- 
financiera del sector público estatal y a las que, en su ámbito territorial, correspondan a los órganos equivalentes a nivel autonómico y local. A estos efectos, la Intervención General de la Administración del Estado, y los órganos equivalentes a nivel autonómico y local, remitirán anualmente a la Oficina Independiente de Regulación y Supervisión un informe global, que se hará público dentro del mes siguiente a su recepción, con los resultados más significativos de su actividad de control en la contratación pública.

Las distintas autoridades de supervisión, designadas por las administraciones competentes en sus respectivos ámbitos territoriales, y la Oficina, que consolidará toda la información, pondrán a disposición del público el resultado del proceso de supervisión, que se publicará en las correspondientes plataformas de contratación.

Gimeno Feliú ha advertido que no se le reconocen a la Oficina competencias de "anulación» o sanción ${ }^{82}$, lo que puede limitar sin duda la eficacia de sus actuaciones.

Junto a la Oficina Independiente, la LCSP 2017 contempla que desarrolle también funciones de control y vigilancia de la contratación pública la Comisión Mixta Congreso-Senado para las Relaciones con el Tribunal de Cuentas, a través de una ponencia de carácter permanente que se debe constituir ${ }^{83}$, señala el apdo. 10 del art. 332 LCSP 2017, «en los términos que dispongan los Reglamentos de las Cámaras». Pero esta misma autonomía de las Cortes que reconoce el precepto hace discutible que la ley de contratos imponga la creación de la ponencia en el seno de la Comisión.

\section{LA COOPERACIÓN ENTRE LOS ESTADOS MIEMBROS: LAS FUNCIONES DEL SISTEMA DE INFORMACIÓN DEL MERCADO INTERIOR EN LA UNIÓN EUROPEA}

La exigencia de una coordinación y cooperación administrativa eficaces está en la base de todo el derecho de la contratación pública de la Unión

82 J. M. Gimeno Feliú, «Las novedades del Proyecto de Ley de Contratos del Sector Publico tras su aprobación en el Congreso de los Diputados», http://www.obcp.es/index. php/mod.opiniones/mem.detalle/id.308/relmenu.3/chk.33b1307605d9e74616e0d e0d3de5956d?utm_source=Registrados+Newsletters\&utm_campaign=327d912d7eNewsletter_JULIO_20170802\&utm_medium $=$ email\&utm_term =0_5b5d3c5dd9327d912d7e-325646537\&ct=t (Newsletter_JULIO_20170802) (consultado el 2 de agosto de 2017).

83 Además de controlar la contratación pública, la Comisión Mixta podrá participar en las iniciativas de mejora normativa que se adopten en esta materia. 
Europea $^{84}$, cuyo objetivo principal es garantizar el respeto de los principios del Tratado de Funcionamiento de la Unión Europea (TFUE) y, en particular, la libre circulación de mercancías, la libertad de establecimiento y la libre prestación de servicios, así como los principios que se derivan de estos, tales como los de igualdad de trato, no discriminación, reconocimiento mutuo, proporcionalidad y transparencia ${ }^{85}$.

Los intercambios de información entre administraciones públicas europeas resultan de especial importancia en lo que se refiere a la comprobación de los motivos de exclusión y de los criterios de selección, y la aplicación de las normas de calidad y medioambientales. En relación con la cooperación administrativa al efecto, hay que tener en cuenta la sujeción a las legislaciones nacionales sobre confidencialidad ${ }^{86}$.

La Directiva 2014/24 no recoge obligaciones específicas de intercambio de información y se remite al efecto al Sistema de Información del Mercado Interior (IMI) establecido por el Reglamento (UE) 1024/2012 ${ }^{87}$, un medio electrónico que puede facilitar la cooperación administrativa sobre la base de procedimientos unificados.

En efecto, el IMI es una herramienta de cooperación online que utilizan autoridades de toda Europa para pedir información a interlocutores de otros países $^{88}$. Desde abril de 2015 se amplió para atender consultas en el contexto de la contratación pública europea ${ }^{89}$.

84 En nuestro ordenamiento jurídico, la jurisprudencia del Tribunal Constitucional ha destacado en una doctrina ya muy consolidada que las fórmulas de cooperación y coordinación administrativa resultan imprescindibles en los supuestos de concurrencia de títulos competenciales (SSTC 32/1983, de 28 de abril, 77/1984, de 3 de julio y 36/1994, de 10 de febrero).

85 Sentencia del TJUE (Sala Quinta) de 16 de abril de 2015, en el asunto C-278/14, ECLI: EU: C: 2015: 228.

86 Puede verse al respecto la sentencia del TJUE (Sala Segunda), de 16 de julio de 2015 , en el asunto C-612/13 P, ECLI: EU: C: 2015: 486.

87 Reglamento (UE) 1024/2012 del Parlamento Europeo y del Consejo, de 25 de octubre de 2012, relativo a la cooperación administrativa a través del Sistema de Información del Mercado Interior y por el que se deroga la Decisión 2008/49/CE de la Comisión (DO L 316 de 14.11.2012, pág. 1).

88 Los flujos de información se pueden establecer entre autoridades públicas y a través de repositorios o bases de datos dentro del IMI a las que pueden acceder todos los usuarios o un grupo determinado de usuarios del sistema. Véase la web del IMI: http:// ec.europa.eu/internal_market/imi-net/index_es.htm (consultado el 27 de febrero de 2017).

89 Véase «La contratación pública en el IMI» en http://ec.europa.eu/internal_market/ imi-net/news/2015/04/index_es.htm (consultado el 27 de febrero de 2017). 
El IMI se puede utilizar en las licitaciones cuando se evalúa a licitadores de otro país europeo para comprobar que un operador es adecuado para ejecutar las obras o prestar los servicios especificados en un contrato dado (especificaciones técnicas requeridas, normas nacionales, etc.); analizar si un contratista, proveedor o prestador de servicios no incurre en ningún motivo de exclusión (por ejemplo, haber sido condenado por fraude); o confirmar la información contenida en la autodeclaración presentada por un licitador ${ }^{90}$. En Espańa, el contacto del IMI se encuentra en el Ministerio de Hacienda y Administraciones Públicas ${ }^{91}$.

90 La utilidad del IMI deriva de su carácter multilingüe, flexible (puede adaptarse a cualquier estructura administrativa, ya sea centralizada o descentralizada) y seguro. Cuenta asimismo con un sistema de protección de datos, su uso no genera costes informáticos para los Estados miembros y las tareas de formación y apoyo corren por cuenta de los coordinadores nacionales del IMI (http://ec.europa.eu/internal_market/imi-net/index_es.htm (consultado el 21 de diciembre de 2016).

91 Véase la web: http://seap.minhap.gob.es/areas/sistema_IMI (consultada el 6 de septiembre de 2017). 
